\title{
Correlative control of early stages of flower bud initiation in 'bourse' shoots of apple (Malus $x$ domestica Borkh. cv. Golden Delicious)
}

\author{
J. Escobedo and J. Crabbé \\ Morphogénèse végétale appliquée, Faculté des Sciences agronomiques, Gembloux, Belgique
}

\section{Introduction}

A better understanding of flowering in fruit trees would be obtained if we could predict where and when a flower is to appear. This is particularly true in those locations where flowering occurs for the first time: they can be predicted (Crabbé, 1984) with a satisfying probability for fruit growers' purposes, but any precise physiological or biochemical approach requires more than mere probability. Consequently, although the start of floral initiation is rather accurately known in fruit species, sound information about floral induction and evocation is still lacking.

As a preliminary to this necessary prediction problem, we began experimenting on apple 'bourse' shoots. The bourse is the swollen basal part of an inflorescence axis at the onset of fruit development; it bears leaves whose axillary buds differentiate and may grow out as shoots. The bourse shoot can flower again in the following years and so, by repeated flowering, a cluster of stacked similar structures appears on old trees. Once formed, a bourse is thus a known site for renewed floral induction. There may be year-to-year irregularities due to competition with fruit growing at the same site (alternate bearing) or with nearby vegetative growth.

Our objectives were to determine what treatments could cause $90-100 \%$ of bourse buds to shift from the vegetative to the floral state and to define precocious signs of this change in meristematic activity.

\section{Materials and Methods}

Six yr old apple trees, cv. Golden delicious, were used throughout. Bourses formed in the current year, on which young fruits were developing, were labeled in early spring. Later, some bourses with short arrested shoots (i.e., spurs) and others with long shoots (ca 20-30 cm) were further selected and treated separately.

Treatments, generally known to increase flower formation, though imperfectly interpreted on physiological grounds, were: branch ringing, young fruit removal from the treated bourse and, on the long bourse shoots, summer pruning. These treatments were applied alone or in combination, at clifferent dates from mid-May to September. 

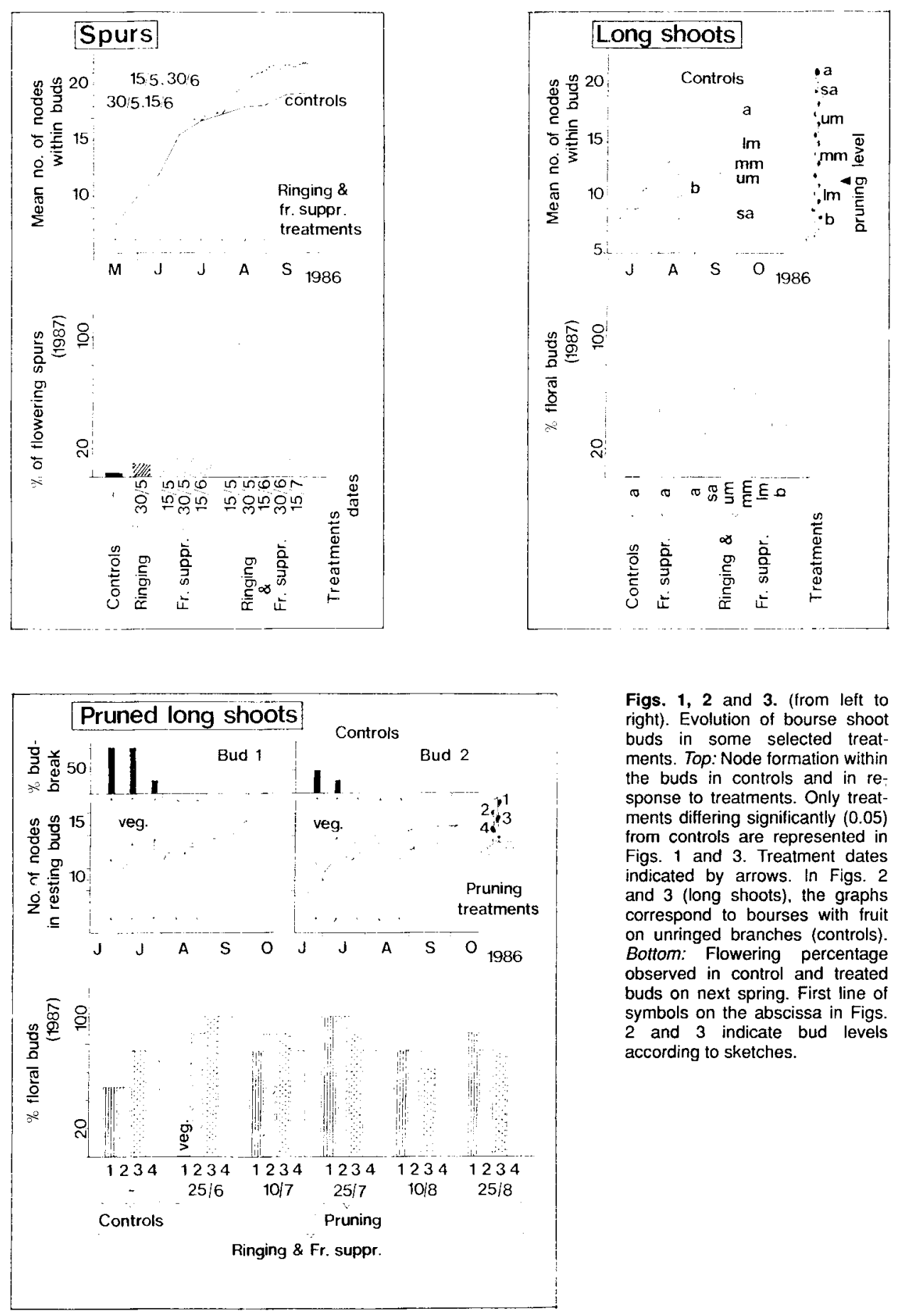

Figs. 1, 2 and 3 . (from left to right). Evolution of bourse shoot buds in some selected treatments. Top: Node formation within the buds in controls and in response to treatments. Only treatments differing significantly $(0.05)$ from controls are represented in Figs. 1 and 3. Treatment dates indicated by arrows. In Figs. 2 and 3 (long shoots), the graphs correspond to bourses with fruit on unringed branches (controls). Bottom: Flowering percentage observed in control and treated buds on next spring. First line of symbols on the abscissa in Figs. 2 and 3 indicate bud levels according to sketches. 
Buds were sampled fortnightly on treated and control branches for dissection and primordia counting, until the plastochron decrease appeared as the earliest sign of floral initiation (Fulford, 1966a, b, c; Abbott, 1977). Terminal buds of spurs and terminal and lateral buds on long shoots, intact or pruned, were considered separately.

\section{Results}

The terminal buds of spurs began to form in early May. So all treatments from midMay to early July appeared to increase node formation within the bud. Nevertheless, branch ringing and fruit suppression needed to be combined to obtain over $90 \%$ flowering (Fig. 1, bottom). The most precocious treatments seemed the most active in terms of percentage of flowering, although those applied from mid-June to early July yielded the fastest response in node number increase (Fig. 1, top). On the average, a bud which reached over 18 nodes at the end of July presumably became floral.

In the selected long shoots, growth arrest occurred after mid-June. At that time, bud formation had already started in lateral buds. However, the terminal bud formed much faster so that, by late August, it already had about 15 nodes, while the laterals lingered around 10-13 (Fig. 2, top). Once again, branch ringing and fruit removal combined, applied in July, brought the terminal to $90 \%$ flowering, but failed to do so for the laterals (Fig. 2, bottom).

But pruning those long shoots, right above the median lateral buds, remarkably increased node formation within these
(Fig. 3, top) and, together with ringing and fruit removal, enabled full completion of floral initiation (Fig. 3, bottom). However, when applied too early, pruning made the uppermost buds break out immediately as leafy shoots. Depending upon the insertion level of the bud, the best time for pruning shifted from late June for the lower buds to late July for the upper ones.

\section{Discussion and Conclusion}

A complete shift of the bourse buds to flower formation was thus obtained by fruit suppression on the bourse plus branch ringing, when applied at a time compatible with the need to shorten the plastochron. For lateral buds on long shoots, pruning was a further requisite.

The enhanced accumulation of nodes within the bud was a good early marker of this shift. But meristematic activation was itself a consequence of even more precocious changes. Our results, repeated during 3 successive years, suggest that we have the experimental system necessary to proceed further in this research.

\section{References}

Abbott D.L. (1977) Fruit bud formation in Cox's Orange Pippin. Annu. Rep. Long Ashton Res. Sta. 1976 167-176

Crabbé J. (1983) Vegetative vigor control over location and fate of flower buds in fruit trees. Acta Hortic. 149, 55-63

Fulford R.M. (1966a, b, c) The morphogenesis of apple buds. I, II, III. Ann. Bot. 29, 167-180; $30,25-38 ; 209-219$ 